\title{
Causes of death in Vanuatu
}

\author{
Karen Carter ${ }^{1,2}$, Viran Tovu ${ }^{3}$, Jeffrey Tila Langati ${ }^{4}$, Michael Buttsworth ${ }^{5}$, Lester Dingley ${ }^{3}$, Andy Calo ${ }^{6}$, \\ Griffith Harrison ${ }^{4}$, Chalapati Rao ${ }^{7,2}$, Alan D. Lopez ${ }^{8}$ and Richard Taylor ${ }^{{ }^{*}}$
}

\begin{abstract}
Background: The population of the Pacific Melanesian country of Vanuatu was 234,000 at the 2009 census. Apart from subsistence activities, economic activity includes tourism and agriculture. Current completeness of vital registration is considered too low to be usable for national statistics; mortality and life expectancy (LE) are derived from indirect demographic estimates from censuses/surveys. Some cause of death (CoD) data are available to provide information on major causes of premature death.

Methods: Deaths 2001-2007 were coded for cause (ICDv10) for ages 0-59 years from: hospital separations (HS) ( $n=636)$, hospital medical certificates (MC) of death $(n=1,169)$, and monthly reports from community health facilities (CHF) $(n=1,212)$. III-defined causes were $3 \%$ for hospital deaths and $20 \%$ from CHF. Proportional mortality was calculated by cause (excluding ill-defined) and age group ( $0-4,5-14$ years), and also by sex for 15-59 years. From total deaths by broad age group and sex from 1999 and 2009 census analyses, community deaths were estimated by deduction of hospital deaths MC. National proportional mortality by cause was estimated by a weighted average of MC and CHF deaths.

Results: National estimates indicate main causes of deaths < 5 years were: perinatal disorders (45 \%) and malaria, diarrhea, and pneumonia (27\%). For 15-59 years, main causes of male deaths were: circulatory disease $27 \%$, neoplasms $13 \%$, injury $13 \%$, liver disease $10 \%$, infection $10 \%$, diabetes $7 \%$, and chronic respiratory disease $7 \%$; and for females: neoplasms $29 \%$, circulatory disease $15 \%$, diabetes $10 \%$, infection $9 \%$, and maternal deaths $8 \%$. Infection included tuberculosis, malaria, and viral hepatitis. Liver disease (including hepatitis and cancer) accounted for $18 \%$ of deaths in adult males and $9 \%$ in females. Non-communicable disease (NCD), including circulatory disease, diabetes, neoplasm, and chronic respiratory disease, accounted for $52 \%$ of premature deaths in adult males and $60 \%$ in females. Injuries accounted for $13 \%$ in adult males and $6 \%$ in females. Maternal deaths translate into an annual maternal mortality ratio of 130/100,000 for the period.
\end{abstract}

Conclusion: Vanuatu manifests a double burden of disease with significant proportional mortality from perinatal disorders and infection/pneumonia $<5$ years and maternal mortality, coupled with significant proportional mortality in adults (15-59 years) from cardiovascular disease (CVD), neoplasms, and diabetes.

Keywords: Vanuatu, Cause of death, Maternal mortality, Child deaths, Adult deaths, Infection, Non-communicable disease

\footnotetext{
* Correspondence: r.taylor@unsw.edu.au

${ }^{9}$ School of Public Health and Community Medicine (SPHCM), University of New South Wales (UNSW), Randwick, Sydney, New South Wales (NSW) 2052, Australia

Full list of author information is available at the end of the article
} 


\section{Background}

The Southwest Pacific Melanesian country of Vanuatu gained independence in 1980, and is composed of an archipelago of mostly volcanic ("high") islands. The population was 234,000 at the 2009 census [1], with over 100 languages represented. The archipelago is located in the Pacific's most southwestern extent of the range of anopheline mosquitoes (the Buxton line) and thus endemic malaria. Apart from subsistence, economic activity includes tourism and agriculture.

Current reporting completeness from routine civil registration and vital statistics (CRVS) systems in Vanuatu are considered too low to enable data to be corrected and used directly to derive estimates of mortality level [1]. Consequently, measures of levels of mortality and LE are derived from demographic estimates from censuses and surveys. Data on mortality level were produced from the Vanuatu Multiple Indicator Cluster Survey (MICS) which in 2007 reported on under-5 year mortality (U5M) and the infant mortality rate (IMR) [2], and Vanuatu has also recently completed a Demographic and Health Survey (DHS) [3]. Demographic analyses of censuses have also produced information on level of mortality using questions on Children Ever Born, Children Surviving (CEBCS) for $<5$ years mortality, with or without adult mortality estimates from parental orphanhood methods to impute model life tables [1, 4] (1989 [5], 1979 [6]). However, neither these surveys nor censuses have collected information on CoD. Empirical data for circa 2010 reports an IMR of around 20/1,000 and life expectancies of 68 years for males and 72 years for females, although these figures may underestimate IMR and overestimate LE [7].

World Health Organization (WHO) reports estimate proportional mortality by $\mathrm{CoD}$ for Vanuatu "based on a combination of country life tables, regional cause of death patterns, and WHO and UNAIDS program estimates for some major causes of death" and "have a high degree of uncertainty" [8]. Similarly, Global Burden of Disease (GBD) estimates are also based on expected patterns of CoD derived from estimated level of mortality and other parameters [9].

However, a variety of CoD data are available from hospital and community deaths in Vanuatu, and these can provide useful information on major causes of premature mortality and hence important public health issues in Vanuatu. Available CoD information from Hospital Separations (HS), medical certification of hospital deaths (MC), and Community Health Facilities (CHF) sources for 2000-2007 is used to generate proportional mortality for CoD by age and sex. Similarities and differences in the resultant CoD distributions for these sources are reviewed, and source-weighted national averages (by age/sex) are estimated to assess the contribution of these disease categories to premature mortality, and to assist with identification of key public health issues contributing to premature mortality in Vanuatu.

\section{Methods \\ Data sources}

De-identified unit record data on deaths for 2000-2007 were obtained during in-country visits from hospital sources with HS (as death) and MC of death (issued at hospitals), and notices of death submitted with monthly nursing reports from CHF below hospital level - area health centers, dispensaries, and aid posts. Certification and reporting of deaths in Vanuatu are discussed in detail in On et al. 2009 [10]. Because of de-identification, the two sources of hospital deaths (HS, MC) were not linkable. Deaths with no age $(n=138)$ and fetal deaths ( $n=248)$ were excluded from all data sources, and hospital deaths $(n=21)$ were removed from community health facility data (Table 1 ). Only deaths $0-59$ years were coded for cause because data quality of CoD data was less for those $\geq 60$ years, LE in Vanuatu is likely to be above 60 years, and this age range includes the demographic adult age bracket $15-59$ years. Ill-defined causes were $2.5-3.5 \%$ in hospital deaths and $19.5 \%$ in CHF deaths for ages $0-59$ years.

\section{Hospital deaths}

For HS, CoD data were collected from the two main hospitals: the national referral hospital at Port Vila on Efate (the main Island), and the secondary district hospital at Luganville, the main town on Espirito Santo $(n=954)$, excluding 27 deaths (no age recorded, and still births) (Table 1). These are the larger two of only three hospitals in Vanuatu routinely staffed by doctors. Hospital separation data were extracted from the Health Information System (HIS). This database is maintained at the national level, but local versions of the database were used as they are considered to be more complete. CoD is recorded according to principal diagnosis, with up to two additional fields for other causes as well as fields for accidents, external causes, and medical procedures. Hospital separation data would normally have the principal diagnosis recorded first, but this field was recorded as the mode of death (cardio-respiratory arrest, heart stopped, stopped breathing, etc.) in many of the cases reviewed, indicating that tabulation based on the first field of the database would have been misleading. The fields appear to have been completed as a causal sequence, as found on a medical certificate, so underlying cause was selected and coded according to ICDv10 rules for medical certificates [11]. Causes were coded by medical record staff at the hospital, with both text and code entered in the database. Medical certificates for hospital deaths are completed semi-routinely (and particularly upon request by family members). During the 
Table 1 Cause of death review, Vanuatu 2000-2007

\begin{tabular}{|c|c|c|c|c|}
\hline \multirow[t]{2}{*}{ Causes of death by age } & \multicolumn{2}{|c|}{ Hospital deaths } & \multirow{2}{*}{$\begin{array}{l}\text { Community health } \\
\text { facility deaths } n(\%)\end{array}$} & \multirow{2}{*}{$\begin{array}{l}\text { National weighted } \\
\text { proportional mortality }\end{array}$} \\
\hline & Hospital separations n (\%) & Medical certificates n (\%) & & \\
\hline $0-4$ years & $147(16 \%)$ & $391(24 \%)$ & $401(17 \%)$ & $18 \%$ \\
\hline Specific causes & 145 & 383 & 311 & \\
\hline IIl-defined \% & $2(1.4)$ & $8(0.6)$ & $90(22.4)$ & \\
\hline $5-14$ years & $35(4 \%)$ & 37 (2 \%) & 73 (3 \%) & $2 \%$ \\
\hline Specific causes & 32 & 36 & 55 & \\
\hline IIl-defined \% & $3(8.6)$ & $1(2.7)$ & $18(24.7)$ & \\
\hline \multirow[t]{2}{*}{$15-59$ years } & M & M & M & \\
\hline & 226 & 301 & 329 & \\
\hline Specific causes & 224 & 291 & 275 & \\
\hline IIl-defined \% & $4(1.8)$ & $22(5.0)$ & $74(18.1)$ & \\
\hline Both sexes $15-59$ years & $454(49 \%)$ & 741 (46 \%) & 738 (31%) & $35 \%$ \\
\hline 0-59 years with cause & $636(69 \%)$ & 1169 (73\%) & $1212(51 \%)$ & \\
\hline Specific causes & 620 & 1128 & 976 & \\
\hline III defined \% & $16(2.5)$ & $41(3.5)$ & $236(19.5)$ & \\
\hline$\geq 60$ years $^{a}$ & 291(31\%) & $443(28 \%)$ & $1182(49 \%)$ & $45 \%$ \\
\hline All ages deaths $0-\geq 60$ years & $927(100 \%)$ & $1612(100 \%)$ & $2394(100 \%)$ & $100 \%$ \\
\hline Deaths excluded from above & & & & \\
\hline Fetal deaths & 13 & 100 & 102 & \\
\hline No age & 14 & 78 & 46 & \\
\hline Hospital deaths & - & - & 21 & \\
\hline All reported deaths & & & & \\
\hline Reported deaths & 954 & 1790 & 2563 & \\
\hline$\%$ deaths with cause $0-59$ years & 97.2 & 90.1 & 93.4 & \\
\hline$\%$ of all Vanuatu deaths ${ }^{\mathrm{b}}$ & 9.6 & 17.3 & 25.2 & \\
\hline
\end{tabular}

Vanuatu national proportional mortality weighted by data sources (MC and CHF) for age groups

${ }^{a}$ Not coded for cause of death. $M$ Male; $F$ Female

${ }^{\mathrm{b}}$ Estimated total deaths from available life tables (excluding fetal deaths)

period of this study, medical certificates were not routinely coded or collated for Luganville, and although collated for Port Vila hospital, were not routinely coded, analyzed, or reported. Data were extracted from the original medical certificates at Luganville hospital and from a spreadsheet maintained by medical records staff at Port Vila hospital $(n=1,790)$. The spreadsheet included all causes listed in Part I of the certificate as text, identified by line. Contributory causes were not recorded. Medical certificates are predominantly completed by the attending doctor. Although almost all certified deaths occurred in hospital, doctors occasionally certified community deaths. Place of death was not well-recorded. Underlying cause was selected and coded (by $\mathrm{KC}$ ) according to ICDv10 [11] (Table 1).

\section{Community health facility deaths}

Deaths in the community are captured through health system reporting by health centers, dispensaries, and aid posts. The locally trained nurses or nurse aides at each facility are required to submit a monthly report of activities including any deaths in their area. A notice of death form is also collected for deaths in the community. This includes name, age, date of death, place of death, and $\mathrm{CoD}$ as a single free-text field. Deaths are collated and coded according to ICDv10 and entered into the national HIS database. Data were sorted according to health facility code, and deaths that occurred in Vila or Luganville hospitals were removed. For deaths where specific age was not recorded, deaths recorded as "adults" were attributed to age group 15-59 years, and "old" or "elderly" to age group $\geq 60$ years. There were 2,563 deaths recorded by CHF between 2001 and 2007, with an average of 366 deaths per year, or approximately $26 \%$ of the expected deaths in Vanuatu based on available life tables [12]. For deaths reported from Port Vila hospital, 21 were removed from the CHF data set; all were adult deaths (13 aged $15-59$ years, and eight aged $\geq 60$ years). 


\section{Analysis}

The approximate proportion of total deaths accounted for by each data set was calculated based on an average of 1,394 deaths per year as estimated by the Vanuatu National Statistics Office [12], assuming little variation over the period under investigation.

Fetal deaths were identified and removed from all data sets: 13 from hospital medical certificates, 100 from hospital separation data, and 102 from community health facility data. Cases where there was uncertainty whether the death was fetal or early neonatal were counted as neonatal, as separate reporting mechanisms exist for stillbirths; in practice they should not be recorded in these data. Deaths without ages were also removed: 14 deaths from medical certificates, 78 from hospital deaths, and 46 deaths from facility data (Table 1 ).

Deaths were tabulated by broad age group: 0-4 years and 5-14 years for both sexes (because of small numbers), $15-59$ years by sex to evaluate differences in CoD distribution by age, and $\geq 60$ years (not coded for CoD). Causes of death were aggregated to ICDv10 General Mortality List One (104 causes), with childhood deaths (0-4 years) aggregated to ICDv10 Condensed List Three for U5M. Tabulations of reported deaths by cause and proportional mortality, excluding unknown and ill-defined deaths, were then calculated for each data source. Exclusion of unknown/ill-defined deaths from analysis of proportional mortality produces the same result as redistribution of deaths by cause.

In order to produce national estimates of proportional mortality by cause, estimated total deaths by broad age group $(<5,5-14,15-59, \geq 60$ years $)$ and sex were derived from census analyses by application of reported annual age- and sex-specific mortality rates to populations (from the 1999 census) [4] and estimated annual deaths by age/sex reported in the 2009 census analytic report [1]. These data were averaged to obtain estimated annual Vanuatu deaths by age/sex for the study period. Average annual community deaths were estimated from total deaths by deduction of annualized MC deaths as the best representation of hospital deaths. This produced source-weights for $<5$ years of 0.33 for $\mathrm{MC}$ and 0.67 for $\mathrm{CHF}$ deaths, and for 5-14 years of 0.15 for $\mathrm{MC}$ and 0.85 for CHF deaths (both sexes); and for 1559 years 0.32 for $\mathrm{MC}$ and 0.68 for $\mathrm{CHF}$ male deaths, and 0.37 for $\mathrm{MC}$ and 0.63 for $\mathrm{CHF}$ female deaths. National proportional mortality by cause was estimated by a weighted average of $\mathrm{MC}$ and $\mathrm{CHF}$ proportional mortality. The national estimate of proportional mortality from maternal mortality was used to estimate maternal deaths from the adult female population, and this was divided by births derived from the 1999 and 2009 census analyses $[1,4]$ to produce a maternal mortality ratio for the period.

\section{Results}

For 2000-2007, there were 954 HS as death (from the two major hospitals) and 1,790 MC (almost all hospital deaths) available for analysis, before exclusions; the age distributions of deaths were similar between the two overlapping hospital sources (Table 1). Deaths reported from CHF $(n=2,563)$ were characterized by a lesser proportion of adult death (15-59 years) and a higher proportion of elderly deaths compared to the hospital sources. Only deaths $<60$ years were coded for CoD. The proportion of ill-defined causes was $<5 \%$ for hospital deaths, but for $\mathrm{CHF}$, ill-defined deaths accounted for $23 \%$ of deaths $<15$ years and $17 \%$ in adults $(15-59$ years). Further, deaths from specific causes in adults, not included in the major causes of death, were 5$10 \%$ for hospital deaths and $22-25 \%$ for community deaths (Table 1).

For females, main causes were neoplasms $29 \%$, circulatory disease $15 \%$, diabetes $10 \%$, infection $9 \%$, and maternal deaths $8 \%$. Infection included tuberculosis $(3 \%$ for both sexes), malaria, and viral hepatitis. Liver disease (including hepatitis and cancer) accounted for $18 \%$ of deaths in adult males and $9 \%$ in females. Circulatory disease and diabetes caused $34 \%$ of adult deaths in males and $25 \%$ in females; with neoplasm and chronic respiratory disease, NCD accounted nationally for $52 \%$ of premature deaths in males and $60 \%$ in females. External causes (injuries) were responsible for $13 \%$ in adult males and $6 \%$ in females. Maternal deaths translate into a maternal mortality ratio of $130 / 100,000$ for the period.

For children $<5$ years the main $\mathrm{CoD}$ were perinatal disorders in all sources of data. Infectious diseases, including diarrhea, malaria, and respiratory disease, especially pneumonia, were more prominent in CHF deaths than in hospital deaths. National estimates for proportional $<5$ years mortality were $45 \%$ perinatal disorders and $27 \%$ infection/pneumonia (Table 2).

For children 5-14 years (only 3-4\% of deaths by source), the most important cause of death in all data sources was infection at 33-45\% of deaths including malaria, meningitis, and respiratory deaths. External causes (injuries) were prominent in hospital medical certificates (19\%) and CHF (24\%) data (Table 2).

For adults (15-59 years), circulatory disease was the most common in males at 27-29\% (by source), and neoplasms were the most common in females at 28$32 \%$ (Table 3 ). The next most common causes of death in males, after circulatory disease, were: neoplasms (12-16\%), external causes (injuries) (9-13\%), then endocrine, metabolic, nutritional, etc. diseases (mostly diabetes) at 6-10\%. National proportional mortality (weighted) for males was: circulatory disease $27 \%$, neoplasms $13 \%$, injury $13 \%$, liver disease $10 \%$, infection $10 \%$, diabetes $7 \%$, and chronic respiratory disease $7 \%$. 
Table 2 Cause of death in children (both sexes), Vanuatu 2000-2007

\begin{tabular}{|c|c|c|c|c|c|c|c|}
\hline \multirow[t]{3}{*}{ Cause of death by age group } & \multicolumn{4}{|c|}{ Hospital deaths } & \multirow{2}{*}{\multicolumn{2}{|c|}{$\begin{array}{l}\text { Community health } \\
\text { facility deaths }\end{array}$}} & \multirow{3}{*}{$\begin{array}{c}\text { National } \\
\text { weighted }^{\mathrm{a}} \\
\text { proportiona } \\
\text { mortality \% }\end{array}$} \\
\hline & \multicolumn{2}{|c|}{ Hospital separations } & \multicolumn{2}{|c|}{ Medical certificates } & & & \\
\hline & No. & $\%$ & No. & $\%$ & No. & $\%$ & \\
\hline \multicolumn{8}{|l|}{ Age $0-4$ years } \\
\hline Infection, parasitic, including & 18 & 12.4 & 21 & 5.5 & 58 & 18.6 & 14.2 \\
\hline Diarrhea & 4 & 2.8 & 8 & 2.1 & 23 & 7.4 & 5.6 \\
\hline Malaria & 7 & 4.8 & 5 & 1.3 & 29 & 9.3 & 6.6 \\
\hline Endocrine, metabolic, nutrition & 4 & 2.8 & 12 & 3.1 & 14 & 4.5 & 4.0 \\
\hline Nervous system & 7 & 4.8 & 5 & 1.3 & 7 & 2.3 & 2.0 \\
\hline Respiratory system, including & 14 & 9.7 & 31 & 8.1 & 63 & 20.3 & 16.2 \\
\hline Pneumonia & 10 & 6.9 & 17 & 4.4 & 51 & 16.4 & 12.4 \\
\hline Perinatal disorders, including & 71 & 49.0 & 232 & 60.6 & 115 & 37.0 & 44.9 \\
\hline Complications of pregnancy, childbirth & 3 & 2.1 & 41 & 10.7 & 40 & 12.9 & 12.2 \\
\hline Low birth weight & 34 & 23.4 & 84 & 21.9 & 24 & 7.7 & 12.4 \\
\hline Intra-uterine hypoxia, birth asphyxia & 16 & 11.0 & 55 & 14.4 & 5 & 1.6 & 5.9 \\
\hline Congenital disorders & 13 & 9.0 & 41 & 10.7 & 19 & 6.1 & 7.6 \\
\hline All other diseases & 2 & 4.8 & 3 & 5.7 & 2 & 5.5 & 5.6 \\
\hline External causes & 7 & 2.8 & 22 & 3.1 & 17 & 4.5 & 4.0 \\
\hline Total specific cause $0-4$ years & 145 & 100.0 & 383 & 100.0 & 311 & 100.0 & 100.0 \\
\hline III-defined excluded & 2 & 1.4 & 8 & 2.0 & 90 & 22.4 & 15.6 \\
\hline \multicolumn{8}{|l|}{ Age $5-14$ years } \\
\hline Infection, parasitic, including & 8 & 22.9 & 8 & 22.2 & 13 & 23.6 & 23.4 \\
\hline Malaria & 4 & 11.4 & 5 & 13.9 & 10 & 18.2 & 17.5 \\
\hline Neoplasms & 4 & 11.4 & 3 & 8.3 & 6 & 10.9 & 10.5 \\
\hline Blood & 1 & 2.9 & 2 & 5.4 & 3 & 4.1 & 4.3 \\
\hline Endocrine, metabolic, nutrition & 4 & 11.4 & 0 & 0.0 & 1 & 1.8 & 1.5 \\
\hline Nervous system, including & 4 & 11.4 & 7 & 19.4 & 5 & 9.1 & 10.7 \\
\hline Meningitis & 3 & 8.6 & 6 & 16.7 & 1 & 1.8 & 4.1 \\
\hline Circulatory system & 5 & 14.3 & 1 & 2.8 & 6 & 10.9 & 9.7 \\
\hline Respiratory system & 1 & 2.9 & 2 & 5.6 & 4 & 7.3 & 7.0 \\
\hline Digestive system & 0 & 0.0 & 1 & 2.8 & 4 & 7.3 & 6.6 \\
\hline Congenital disorders & 3 & 8.6 & 1 & 2.8 & 0 & 0.0 & 0.4 \\
\hline All other diseases & 1 & 2.9 & 4 & 11.1 & 0 & 0.0 & 1.7 \\
\hline External causes & 1 & 2.9 & 7 & 19.4 & 13 & 23.6 & 23.0 \\
\hline Total specific cause $5-14$ years & 35 & 100.0 & 36 & 100.0 & 55 & 100.0 & 100.0 \\
\hline IIl-defined excluded & 3 & 8.6 & 1 & 2.7 & 18 & 24.7 & 21.3 \\
\hline
\end{tabular}

Cause of death according to ICDv10 General Mortality List 1 for Chapters and causes of interest with sufficient deaths. Proportional mortality by cause calculated excluding (1-094) ill-defined and unknown. Hospital deaths: Hospital Separations (HS) as deceased. Medical Certificate (MC) of death. Community Health Facility (CHF): reporting of deaths (excluding hospitals).

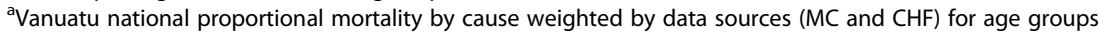

For females, the next most common causes of adult deaths after neoplasms were circulatory disease (14$16 \%)$, then endocrine, metabolic, nutritional, etc. (mostly diabetes) at 10-13\%. National proportional mortality (weighted) for females was: neoplasms $29 \%$, circulatory disease $15 \%$, diabetes $10 \%$, infection $9 \%$, and maternal deaths $8 \%$.
Infection in adults included tuberculosis $(3 \%$ for both sexes), malaria, and viral hepatitis. Liver disease (including hepatitis and cancer) accounted for $18 \%$ of deaths in adult males and $9 \%$ in females. Circulatory disease and diabetes caused $34 \%$ of adult deaths in males and $25 \%$ in females; with neoplasm and chronic respiratory disease, NCD accounted nationally for $52 \%$ of premature adult 
Table 3 Adult proportional mortality by cause 15-59 years, Vanuatu 2000-2007

\begin{tabular}{|c|c|c|c|c|c|c|c|c|c|c|c|c|c|c|}
\hline \multirow[t]{4}{*}{ Cause of death } & \multicolumn{7}{|c|}{ Males } & \multicolumn{7}{|c|}{ Females } \\
\hline & \multicolumn{3}{|c|}{ Reported deaths } & \multicolumn{4}{|c|}{ Proportional mortality (\%) } & \multicolumn{3}{|c|}{ Reported deaths } & \multicolumn{4}{|c|}{ Proportional mortality (\%) } \\
\hline & \multicolumn{2}{|c|}{ Hospital } & \multirow[t]{2}{*}{$\mathrm{CHF}$} & \multicolumn{2}{|c|}{ Hospital } & \multirow[t]{2}{*}{$\mathrm{CHF}$} & \multirow[b]{2}{*}{$\operatorname{Van}^{\mathrm{b}}$} & \multicolumn{2}{|c|}{ Hospital } & \multirow[t]{2}{*}{$\mathrm{CHF}$} & \multicolumn{2}{|c|}{ Hospital } & \multirow[t]{2}{*}{$\mathrm{CHF}$} & \multirow[b]{2}{*}{$\operatorname{Van}^{\mathrm{b}}$} \\
\hline & $\mathrm{HS}$ & $M C$ & & HS & $\overline{M C}$ & & & $\mathrm{HS}$ & $M C$ & & HS & $M C$ & & \\
\hline Infection & 21 & 41 & 32 & 9.3 & 9.8 & 9.6 & 9.7 & 22 & 27 & 23 & 10.1 & 9.1 & 8.4 & 8.7 \\
\hline Respiratory TB & 3 & 4 & 9 & 1.3 & 1.0 & 2.7 & 2.2 & 1 & 5 & 8 & 0.5 & 1.7 & 2.9 & 2.5 \\
\hline Other TB & 1 & 3 & 1 & 0.4 & 0.7 & 0.3 & 0.4 & 4 & 3 & - & 1.8 & 1.0 & - & 0.4 \\
\hline Viral hep & 6 & 20 & 7 & 2.7 & 4.8 & 2.1 & 3.0 & 4 & 4 & 5 & 1.8 & 1.4 & 1.8 & 1.7 \\
\hline AIDS & - & 1 & - & - & 0.2 & - & 0.1 & - & - & - & - & - & - & - \\
\hline Malaria & 4 & 2 & 10 & 1.8 & 0.5 & 3.0 & 2.2 & 4 & 5 & 7 & 1.8 & 1.7 & 2.5 & 2.2 \\
\hline Neoplasms & 35 & 48 & 47 & 15.5 & 11.5 & 14.1 & 13.3 & 66 & 91 & 77 & 30.3 & 31.5 & 28.0 & 29.3 \\
\hline Liver etc & 10 & 20 & 14 & 4.5 & 4.8 & 4.2 & 4.4 & 5 & 3 & 8 & 2.3 & 1.0 & 2.9 & 2.2 \\
\hline Breast & - & 1 & - & - & 0.2 & - & - & 9 & 27 & 10 & 4.1 & 9.4 & 3.6 & 5.7 \\
\hline Cervix uteri & - & - & - & - & - & - & - & 13 & 20 & 7 & 5.9 & 7.0 & 2.5 & 4.2 \\
\hline Endocrine etc. & 16 & 41 & 19 & 7.1 & 9.9 & 5.7 & 7.0 & 29 & 28 & 31 & 13.3 & 9.8 & 11.3 & 10.7 \\
\hline Diabetes & 16 & 40 & 18 & 7.1 & 9.7 & 5.4 & 6.8 & 28 & 28 & 29 & 12.8 & 9.8 & 10.5 & 10.2 \\
\hline Nervous system & 5 & 11 & 16 & 2.2 & 2.6 & 4.8 & 4.1 & 3 & 6 & 8 & 1.4 & 2.0 & 2.9 & 2.6 \\
\hline Circulatory dis & 64 & 119 & 89 & 28.5 & 28.8 & 26.6 & 27.3 & 34 & 46 & 39 & 15.5 & 16.0 & 14.2 & 14.9 \\
\hline Rheumatic & 3 & 7 & - & 1.3 & 1.7 & - & - & 7 & 13 & - & 3.2 & 4.5 & - & - \\
\hline Hypertensive & 7 & 5 & 2 & 3.1 & 1.2 & 0.6 & 0.8 & 2 & 2 & 4 & 0.9 & 0.7 & 1.5 & 1.2 \\
\hline $\mathrm{IHD}$ & 15 & 51 & 2 & 6.7 & 12.3 & 0.6 & 4.3 & 4 & 7 & - & 1.8 & 2.4 & - & - \\
\hline Other heart & 26 & 33 & 71 & 11.6 & 8 & 21.2 & 17.0 & 9 & 10 & 24 & 4.1 & 3.5 & 8.7 & 6.8 \\
\hline Stroke & 13 & 21 & 14 & 5.8 & 5.1 & 4.2 & 4.5 & 12 & 12 & 11 & 5.5 & 4.2 & 4.0 & 4.1 \\
\hline Respiratory dis & 19 & 34 & 24 & 8.5 & 8.2 & 7.2 & 7.5 & 16 & 18 & 19 & 7.3 & 6.2 & 7.0 & 6.7 \\
\hline COPD & 10 & 21 & 18 & 4.5 & 5.1 & 5.4 & 5.3 & 9 & 13 & 14 & 4.1 & 4.5 & 5.1 & 4.9 \\
\hline Alimentary dis & 23 & 33 & 46 & 10.3 & 7.9 & 13.7 & 11.9 & 10 & 15 & 19 & 4.6 & 5.2 & 6.9 & 6.3 \\
\hline Liver disease & 21 & 29 & 40 & 9.4 & 7.0 & 11.9 & 10.4 & 7 & 10 & 16 & 3.2 & 3.5 & 5.8 & 5.0 \\
\hline Genito-urinary & 14 & 21 & 10 & 6.3 & 5.1 & 3.0 & 3.7 & 23 & 21 & 11 & 10.5 & 7.3 & 4.0 & 5.2 \\
\hline Maternal & - & - & - & - & - & - & - & 7 & 13 & 28 & 3.2 & 4.5 & 10.2 & 8.1 \\
\hline External & 20 & 52 & 42 & 8.8 & 12.6 & 12.6 & 12.6 & 3 & 17 & 15 & 1.4 & 5.8 & 5.6 & 5.7 \\
\hline MVA & 9 & 8 & 3 & 4.0 & 1.9 & 0.9 & 1.2 & - & 1 & - & - & 0.3 & - & - \\
\hline Drowning & 3 & 9 & 9 & 1.3 & 2.2 & 2.7 & 2.5 & - & - & 3 & - & - & 1.1 & 0.7 \\
\hline Assault & 1 & 8 & 7 & 0.4 & 1.9 & 2.1 & 2.0 & 2 & 4 & 5 & 0.9 & 1.4 & 1.8 & 1.7 \\
\hline Other causes & 11 & 40 & 84 & 4.9 & 9.6 & 25.1 & 20.2 & 13 & 19 & 59 & 5.9 & 6.5 & 21.5 & 16.0 \\
\hline All specific cause & 224 & 418 & 335 & & & & & 219 & 291 & 275 & & & & \\
\hline III-defined ${ }^{a}$ excluded & 4 & 22 & 74 & 1.8 & 5.0 & 18.1 & & 7 & 10 & 54 & 3.1 & 3.3 & 16.4 & \\
\hline
\end{tabular}

Cause of death according to ICDv10 Chapters and causes of interest with sufficient deaths; COPD Chronic Obstructive Pulmonary Disease HS Hospital separations as deceased; MC Medical certificate of hospital death; CHF Community Health Facility (excluding hospitals) deaths

aProportional mortality by cause calculated excluding (1-094) ill-defined and unknown

banuatu national proportional mortality by cause weighted by data sources (MC and CHF) for age group by sex

deaths in males and $60 \%$ in females. External causes (injuries) were responsible for $13 \%$ in adult males and $6 \%$ in females.

Maternal deaths were responsible for $10 \%$ of adult female deaths in CHF, and 3-5 \% in hospital data sources, with a weighted national average of $8 \%$. This translates to approximately 8.2 deaths per year for the country for the period under study, which produces a maternal mortality ratio of 130 per 100,000 births (from the 1999 and 2009 censuses).

\section{Discussion}

This study reports empirical cause of death patterns from Vanuatu based on age 0-59 years from hospital and 
community health facility data sources. Deaths in the HS data overlap those from MC on deaths in hospital and provide two similar perspectives on cause of death patterns from hospital sources. The age distributions of death (all ages) and proportional mortality for the main causes in adults by age group ( $0-59$ years) for hospital deaths are quite similar, providing some cross validation of representativeness and validity of the two hospital sources. However, the $\mathrm{MC}$ data may be reliable and valid due to larger coverage for the same period and certification by a medical doctor, even though it contains a few community deaths for which a medical certificate of death was sought. For all deaths from CHF, proportional distribution of deaths by age was lower for age $15-59$ years $(31 \%)$ compared to hospital sources (46-49\%), and higher for age $\geq 60$ years $(49 \%)$ compared to hospital sources (28-31\%). For age 0-4 years, proportional mortality from infectious diseases was higher from CHF (19\%) than hospital sources (6-12\%), as was respiratory disease (20\%) compared to hospital sources (8-10 \%). In adults aged 15-59 years, proportional mortality was remarkably similar for major causes of death from CHF compared to hospital sources, except for maternal deaths which were $10 \%$ in CHF compared to 3-5 \% from hospital sources. In 0-59 year olds, ill-defined causes were evident in $20 \%$ of CHF, whereas for hospital sources the proportion was 3-4\%. Deaths with ill-defined cause were excluded from calculation of proportion mortality from specific causes. Deaths from specific causes in adults, not included in the major causes of death, were $22-25 \%$ for community deaths and $5-10 \%$ for hospital deaths. Certification and reporting of deaths in Vanuatu are discussed in detail in On et al. 2009 [10].

For deaths among those aged $0-4$, all sources of data reflect the importance of neonatal causes of death, demonstrating the importance of antenatal care, appropriate delivery services, improved maternal health, and good quality neonatal care $[13,14]$ in reducing mortality in this age group. Infectious diseases (pneumonia, malaria, meningitis, and diarrhea) represent a significant proportion of deaths in this age group, as reported by all sources. The 2013 DHS indicated that for children $<5$ years in the two weeks prior to the survey: $3 \%$ had symptoms of acute respiratory infection, $13 \%$ of children had fever, and $12 \%$ had diarrhea [3]. At the DHS survey, $28 \%$ showed evidence of stunting, $4 \%$ wasting, $11 \%$ underweight, and $2 \%$ were obese for their age [3]. This highlights the importance of programs such as the Integrated Management of Childhood Illnesses (IMCI) programs [15], to target these areas at a community level to accelerate progress towards reducing infant and childhood mortality under the post-2015 Sustainable Development Goals (SDGs), having failed to reach the Millennium Development Goals (MDGs) for these indices. For 5-14-year-olds, small numbers preclude detailed analysis, but the most common CoD were infection-related. External causes were also prominent in some data sources.

The leading causes of death for adults aged 15-59 were circulatory disease, neoplasms, diabetes, and liver diseases. Differences in cause distribution between "other heart diseases" and specific diagnoses (e.g., ischemic heart disease and cerebrovascular disease) between sources in this age group possibly reflect both more accurate reporting by doctors on the medical certificates and greater likelihood of these deaths being recorded as non-specific heart disease in community health facility reports by nurses and nursing aides - rather than reflecting a true difference in underlying disease patterns. For adult females, cervical and breast cancer rank highly as CoD in both the hospital and health facility data. NCDs were the leading causes of premature death for adults in both sexes in the 15-59 age group. For males, these were predominantly CVD and diabetes, while for females, neoplasms were the most important $\mathrm{CoD}$ followed by CVD and diabetes.

Compared to hospital sources, deaths in CHF had higher proportions of elderly ( $\geq 60$ years) deaths coded as ill-defined ( $20 \%$ ) for $0-59$ years, and higher CoD proportions due to infectious and respiratory diseases in children $<5$ years. This indicates the importance of CHF data for providing information on out-of-hospital deaths, particularly for children and the elderly, and the need to improve diagnostic specificity for CHF deaths.

The GBD 2010 estimates rank CoD for Vanuatu as: stroke $(7.4 \%)$, lower respiratory disease $(6.9 \%)$, ischemic heart disease (6.3\%), diabetes (5.5\%), preterm birth complications $(4.3 \%)$, diarrheal disease (3.2\%), tuberculosis $(2.7 \%)$, and road injury (2.5\%), measured as proportion of total years of life lost (YLL) [9]. Thus around $20 \%$ of YLL are due to CVD or diabetes.

Although it is not possible to provide national estimates of cause-specific mortality rates per population due to the uncertainty in existing data collections (both for level and cause of mortality), the data presented in this paper clearly demonstrate Vanuatu is dealing with a double burden of disease, with significant proportions of mortality attributed to infectious diseases, perinatal, and maternal mortality for Group I, and non-communicable disease (NCD) as Group II conditions [16]. While the significant proportion of NCDs in adults from CHF data may, in part, be attributed to reporting of non-specific causes such as "heart problem" and "heart-stopped," this pattern is also reflected in the hospital deaths and adds to the evidence that the mortality burden from NCDs is significant. The significant proportion of deaths attributed to NCDs in adults aged 15-59 years, including CVD and diabetes, is consistent with patterns seen in other Pacific states such as Nauru [17], Tonga [18, 19], and Fiji [20, 21], where NCDs have 
contributed to elevated premature adult mortality and thus limited improvements in LE [7].

The significant proportion of "other cancers" reported in Vanuatu adults is attributable, at least in part, to a prominence of thyroid cancer which is consistent with published incidence data for Vanuatu, and is not dissimilar to several other Pacific Island populations [22, 23]. Previous studies report a higher incidence in Vanuatu of cervical cancer and high-grade epithelial abnormalities (2\%) on screening than Australia [24], which is consistent with findings that show cervical cancer as an important $\mathrm{CoD}$ in adult females. Screening is, however, very limited, and human papillomavirus (HPV) vaccine, which would benefit future generations of women, is not yet generally available.

The deaths from liver disease and liver cancer are most likely associated with viral hepatitis, although $\mathrm{CoD}$ is not available at this level. Hepatitis B antigen carriage in adults $\geq 20$ years was reported as $15 \%$ in 1989 [25] and $25 \%$ in adult women (mothers) in 1991 [26]. Successful immunization for hepatitis B in ni-Vanuatu children since the 1990s [27, 28] should lead to fewer cases of liver disease in adults in the next generation.

Deaths from external causes appear underrepresented in the hospital separation data (but not the MC or CHF data), possibly because they died at the scene or were dead on arrival (and hence not admitted to hospital), and as such may not have been adequately considered in public health priorities.

Maternal deaths were $10 \%$ of adult female deaths 15-59 years in CHF and $4-5 \%$ in hospital data, or $8 \%$ as a weighted national estimate. This translates into a maternal mortality ratio of $130 / 100,000$ births for $2000-2009$. The hospital maternal mortality ratio was reported as $70 / 10^{5}$ births from the labor ward at Port Vila hospital for 1979-2001 [29]. Modelled estimates of maternal mortality in Vanuatu are reported as $230 / 100,000$ in 2000 and 178 in 2008 [30]. The Vanuatu MICS in 2007 [2] reported that $24 \%$ of women were married before 18 years of age, $92 \%$ of urban births were in health facilities and $78 \%$ in rural areas, and $87 \%$ of urban births were delivered by skilled personnel, while in rural areas it was $72 \%$. The 2009 census reported that the adolescent (15-19 years) fertility rate was higher in rural $(77 / 1000)$ than urban areas (40/1000) [1]. These data are congruent with the higher proportional maternal mortality from community health facility deaths compared to hospital deaths in Vanuatu.

Despite data shortcomings, findings presented here provide national-level $\mathrm{CoD}$ data that can assist health planners and donor agencies ensure that health assessment and intervention programs are more accurately targeted towards diseases and conditions responsible for the greatest proportions of premature mortality.
Furthermore, this analysis highlights the strengths and weaknesses of the various data sets available, and indicates how they how they should be improved and could be used in future analyses.

\section{Conclusion}

Vanuatu manifests a double burden of disease with significant proportional mortality from perinatal disorders and infection/pneumonia $<5$ years and maternal mortality, indicative of a pre-transitional pattern, coupled with significant proportional mortality in adults aged 15-59 years from CVD, neoplasms, and diabetes suggestive of later stages in the epidemiological transition.

\section{Abbreviations}

ADRAS: Australian development research award; ANU: Australian National University; CEBCS: children ever-born and children surviving; CHF: community health facilities; CoD: cause of death; CRVS: civil registration and vital statistics; CVD: cardiovascular disease; DFAT: department of foreign affairs and trade; DHS: demographic and health survey; HIS: health Information system; HPV: human papillomavirus; HS: hospital separations; IHME: institute for health metrics and evaluation; IMCI: integrated management of childhood illnesses; IMR: infant mortality rate; LE: life expectancy; MDG: millennium development goal; MICS: multiple indicator cluster survey; $\mathrm{MoH}$ : vanuatu ministry of health; MS: medical certificates; NCD: non-communicable disease; SPC: secretariat of the pacific community; SPH: school of population health; SPHCM: school of public health and community medicine; U5M: under-5 mortality; VNSO: vanuatu national statistics office; WHO: World Health Organization; YLL: years of life lost.

\section{Competing interests}

None of the authors have competing financial or non-financial competing interests.

\section{Authors' contributions}

KC made substantial contributions to conception and design, acquisition, analysis and interpretation of data, and has been involved in drafting and revision of the manuscript for important intellectual content. VT, JTL, MB, LD, $A C$, and $\mathrm{GH}$ made important contributions to acquisition and/or analysis of data. CR, AL and RT made substantial contributions to conception and design, analysis and interpretation of data, and have been involved in critical revision of the manuscript for important intellectual content. All authors have given final approval of the version to be published and agree to be accountable for all aspects of the work in ensuring that questions related to the accuracy or integrity of any part of the work are appropriately investigated and resolved.

\section{Acknowledgments}

Funding for this work was provided under an Australian Development Research Award (Grant no: 44738) provided by AusAID, now incorporated into the Australian Department of Foreign Affairs and Trade (DFAT).

\section{Author details \\ ${ }^{1}$ Secretariat of the Pacific Community (SPC), B.P. D5, Nouméa Cedex 98848, New Caledonia. ${ }^{2}$ School of Population Health (SPH), Faculty of Health Sciences, University of Queensland (UQ), St Lucia, Brisbane, Queensland 4072, Australia. ${ }^{3}$ Ministry of Health $(\mathrm{MoH})$, Port Vila, Vanuatu. ${ }^{4}$ Formerly, Ministry of Health $(\mathrm{MoH})$, Port Vila, Vanuatu. ${ }^{5}$ World Health Organisation, Vanuatu office, Port Vila, Vanuatu. ${ }^{6}$ National Statistics Office, Port Vila, Vanuatu. ${ }^{7}$ National Centre for Epidemiology and Population Health, Research School of Population Health, Australian National University (ANU), Acton, Canberra, Australian Capital Territory (ACT) 2601, Australia. ${ }^{8}$ Melbourne School of Population and Global Health, University of Melbourne, Parkville, Melbourne, Victoria 3010, Australia. ${ }^{9}$ School of Public Health and Community Medicine (SPHCM), University of New South Wales (UNSW), Randwick, Sydney, New South Wales (NSW) 2052, Australia.}




\section{References}

1. Vanuatu 2009 census. Volume 2, summary report in national population and housing census analytic report. Vanuatu national statistics office (VNSO) 2011.

2. Vanuatu Multiple Indicator Cluster Survey (MICS) 2007. Vanuatu Ministry of Health, UNICEF. Port Vila: Government of Vanuatu, 2008. http://www.unicef. org/pacificislands/MICS_Reportsmla.pdf. Accessed 7 March 2016.

3. Vanuatu Demographic and Health Survey, 2013. VNSO and SPC, Noumea, New Caledonia, 2014

4. Vanuatu census. 1999 National Population Census: Demographic Analysis Report. In: Office NS, Editor: Republic of Vanuatu; 2001. Seattle, USA

5. National Population Census 1989: Demographic and Migration Analysis. In: Office NS, Editor: Government of Vanuatu; 1993.

6. Booth H. Fertility and Mortality in Vanuatu: The demographic analysis of the 1979 Census. Pacific Population Paper No. 1. Noumea: South Pacific Commission; 1985.

7. Linhart C, Carter K, Taylor R, Rao C, Lopez A. Mortality Trends in Pacific Island States. School of Public Health and Community Medicine (SPHCM), University of NSW (UNSW), Sydney Australia; Secretariat for the Pacific Community (SPC), Noumea, New Caledonia; University of Queensland (UQ), Brisbane. Australia; June 2014. https://sphcm.med.unsw.edu.au/centresunits/international-ncd-research-group/downloads. Accessed 7 March 2016.

8. WHO NCD Country Profiles Vanuatu (pdf). 2011. http://www.who.int/nmh/ countries/vut_en.pdf. Accessed 7 March 2016.

9. Institute for Health Metrics and Evaluation (IHME). Global Burden of Disease Country Profiles. Vanuatu 2010. http://www.healthdata.org/results/countryprofiles. Accessed 7 March 2016.

10. On ML, Bennett V, Whittaker M. Health information systems in the Pacific: a case study of Vanuatu. In: Documentation Note Series, Number 3. Health Information Systems Knowledge Hub, School of Population Health, The University of Queensland. November 2009. http://www.uq.edu.au/hishub/ docs/DN03/HISHUB-DN03-08-WEB-7Mar12.pdf. Accessed 7 March 2016.

11. WHO. International Classification of Diseases. ICD10 UPDATE. 2011;10. 2011. http://www.who.int/classifications/icd/icd10updates/en/. Accessed 7 March 2016

12. Vanuatu National Statistics Office. 2009 Census Analytical Report (Volume 2). http://www.vnso.gov.vu/index.php/documentlibrary?view=download\&fileld=2009. Accessed 7 March 2016

13. Dickson KE, Simen-Kapeu A, Kinney MV, Huicho L, Vesel L, Lackritz E, de Graft Johnson J, von Xylander S, Rafique N, Sylla M, Mwansambo C, Daelmans B, Lawn JE. Every Newborn: health-systems bottlenecks and strategies to accelerate scale-up in countries. Lancet. 2014;384(9941):438-54.

14. Bhutta ZA, Das JK, Bahl R, Lawn JE, Salam RA, Paul VK, Sankar MJ, Blencowe $H$, Rizvi A, Chou VB, Walker N. Can available interventions end preventable deaths in mothers, newborn babies, and stillbirths, and at what cost? Lancet. 2014;384(9940):347-70.

15. WHO. Integrated Management of Childhood Illness (IMCI). http://www.who. int/maternal_child_adolescent/topics/child/imci/en/. Accessed 7 March 2016.

16. Lozano R, Naghavi M, Foreman K, Lim S, Shibuya K, Aboyans V, et al. Global and regional mortality from 235 causes of death for 20 age groups in 1990 and 2010: a systematic analysis for the Global Burden of Disease Study 2010 Lancet. 2012;380:2095-128.

17. Carter K, Soakai TS, Taylor R, Gadabu I, Rao C, Thoma K, et al. Mortality trends and the epidemiological transition in Nauru. Asia Pac J Public Health. 2011;23(1):10-23. Epub 2010/12/21.

18. Carter KL, Hufanga S, Rao C, Akauola S, Lopez AD, Rampitage R, et al. Causes of death in Tonga: quality of certification and implications for statistics. Popul Health Metr. 2012;10(4):1-15. doi:10.1186/1478-7954-10-4 http://www.pophealthmetrics.com/content/pdf/1478-7954-10-4.pdf. Accessed 7 March 2016.

19. Hufanga S, Carter KL, Rao C, Lopez AD, Taylor R. Mortality trends in Tonga: an assessment based on a synthesis of local data. Popul Health Metrics. 2012;10(1):14. doi:10.1186/1478-7954-10-14.

20. Taylor R, Carter K, Naidu S, Linhart C, Azim S, Rao C, et al. Divergent mortality trends by ethnicity in Fiji. Aust NZ J Public Health. 2013;37(6):509-15.

21. Carter K, Cornelius M, Taylor R, Ali S, Rao C, Lopez A, et al. Mortality trends in Fiji. Aust NZ J Public Health. 2011;35(5):412-20.

22. Paksoy N, Montaville B, McCarthy SW. Cancer occurrence in Vanuatu in the South Pacific, 1980-86. Trop Geogr Med. 1990;42(2):157-61.

23. Paksoy N. Frequency of Thyroid Cancer in Pacific Populations. J Natl Cancer I. 1992;84(14):1124-5.
24. Fotinatos $\mathrm{N}$, Warmington A, Walker T, Pilbeam M. Estimates for cervical abnormalities in Vanuatu. Aust NZ J Public Health. 2007;31(6):571-5.

25. Taylor R, Montaville B, Levy S, Gust I, Moreau JP, Dimitrakakis M, et al. Hepatitis B infection in Vanuatu: age of acquisition of infection and possible routes of transmission. Asia Pac J Public Health. 1989;3(3):205-12.

26. Maher CP, Harris MS, Milne A, Johnston A, Stewart A, Waldon JA. Seroepidemiology of hepatitis B infection in children in Vanuatu. Implications for vaccination strategy. Med J Australia. 1991;154(4):249-53.

27. Wilson N, Ruff TA, Rana BJ, Leydon J, Locarnini S. The effectiveness of the infant hepatitis B immunisation program in Fiji, Kiribati. Tonga and Vanuatu Vaccine. 2000;18(26):3059-66.

28. Basuni AA, Butterworth L, Cooksley G, Locarnini S, Carman WF. Prevalence of HBsAg mutants and impact of hepatitis B infant immunisation in four Pacific Island countries. Vaccine. 2004;22(21-22):2791-9.

29. Grace RF, Vurobaravu TS. Twenty-three years of labour floor records, Vila Central Hospital, Vanuatu. Aust N Z J Obstet Gynaecol. 2003;43(2):157-9.

30. Hogan MC, Foreman KJ, Naghavi M, Ahn SY, Wang M, Makela SM, et al. Maternal mortality for 181 countries, 1980-2008: a systematic analysis of progress towards Millennium Development Goal 5. Lancet. 2010;375(9726): 1609-23.

\section{Submit your next manuscript to BioMed Central and we will help you at every step:}

- We accept pre-submission inquiries

- Our selector tool helps you to find the most relevant journal

- We provide round the clock customer support

- Convenient online submission

- Thorough peer review

- Inclusion in PubMed and all major indexing services

- Maximum visibility for your research

Submit your manuscript at www.biomedcentral.com/submit

) Biomed Central 